\title{
$\int \mathrm{COM}$
}

\section{Lars Guenther and Marina Joubert}

\begin{abstract}
Research in the field of science communication started emerging about 50 years ago and has since then matured as a field of academic enquiry. Early findings about research-active authors and countries reveal that scholarly activity in the field has traditionally been dominated by male authors from English-speaking countries in the West. The current study is a systematic, bibliographic analysis of a full sample of research papers that were published in the three most prominent journals in the field from 1979 to 2016. The findings reveal that early inequities remain prevalent, but also that there are indications that recent increases in research outputs and trends in authorship patterns - for example the growth in female authorship - are beginning to correct some of these imbalances. Furthermore, the current study verifies earlier indications that science communication research is becoming increasingly institutionalised and internationalised, as demonstrated by an upward trend in papers reflecting cross-institutional collaboration and the diversity of countries where authors are based.
\end{abstract}

Keywords

History of public communication of science; Scholarly communication; Science communication in the developing world

Science communication is a dynamic, interdisciplinary field of research that draws from a wide range of disciplines and encompasses a wide spectrum of scientific approaches [Schiele, Claessens and Shi, 2012a]. It employs tools and techniques from social and behavioural sciences, as well as from humanities; while scholars in the field are typically trained in social science disciplines such as sociology, communication studies, media studies, or in related fields of humanities such as philosophy or rhetoric [Hornig Priest, 2007; Hornig Priest, 2010].

As a maturing field of scholarly enquiry, science communication is informed by more than 50 years of research [Gascoigne et al., 2010; Trench and Bucchi, 2015]. Research in this field aims to improve our understanding of the best ways to communicate complex information, in particular to people who are outside the arena of scientific research [Hornig Priest, 2010]. Therefore, much of what we know about the science behind science communication and best practice in the field emanates from a comprehensive body of theoretical considerations and empirical research in this field. Based on the intellectual productivity of the field and the 
widespread offering of university courses in science communication, ranging from undergraduate to doctoral level degrees, Schiele, Claessens and Shi [2012a, p. xxiv] contend that public communication of science and technology "is in the process of becoming a fully separate academic discipline".

Science communication has become widely recognised as a global phenomenon, incorporating the work of many scholars with diverse (research) backgrounds [e.g. Bucchi and Trench, 2014; Burns, O'Connor and Stocklmayer, 2003; Schiele, Claessens and Shi, 2012a; Trench and Bucchi, 2010]. The plurality of scholarly activity in the field is reflected in the research outputs, including the scientific articles that are published in the main journals dedicated to the field of science communication. However, despite the increasingly global nature of science communication, research activities in the field are shaped by national priorities and cultural contexts [Schiele, Claessens and Shi, 2012a] and research outputs therefore display regional differences.

From a historical point of view, several trends and observations have been described over the last few decades: First of all, the productivity of scholars in the field of science communication has increased significantly [e.g. Bauer and Howard, 2013; Borchelt, 2012]. The analysis by Trench and Bucchi [2015] of the geographic locations of the research contributions included in their anthology [Bucchi and Trench, 2014] reveal a positive trend in terms of both cross-institutional and cross-country collaborations - i.e. there has been an increase in multi-authored papers where authors are based at more than one institution (increasing institutionalisation), as well as a growth in the number of collaborative, multi-country studies (increasing internationalisation). The same authors also demonstrate the increasing gender diversity of authors. Irrespective of these trends, many scholars agree that scholars from Western, English-speaking countries continue to dominate the field [e.g. Bauer and Howard, 2013; Borchelt, 2012]. However, the bibliographic characteristics of science communication research outputs have rarely been analysed in a systematic way, despite the view that such overviews of research fields are important in identifying trends and challenges [Schäfer, 2012], or for defining a discipline [Gascoigne et al., 2010].

Drawn from recent discussions about the visibility and viability of science communication as a field of research and teaching, as well as patterns of authorship, the geographical spread of authors and their gender [e.g. Borchelt, 2012; Bucchi and Trench, 2014; Trench and Bucchi, 2015], the present study presents an extended, systematic analysis of peer-reviewed research outputs in science communication to shed new light on current trends in this field of research. Research papers that have been published in the three main journals of the field Science Communication: Linking Theory and Practice, ${ }^{1}$ Public Understanding of Science, and the Journal of Science Communication ${ }^{2}$ - since 1979 (the launch of the first journal) up until 2016, were analysed according to bibliographic data to identify trends in publication rates and patterns of authorship, as well as the geographical spread and gender balance of authors. Such a systematic analysis of research outputs makes it possible to highlight research gaps and challenges, and to inform future research priorities [Schäfer, 2012].

\footnotetext{
${ }^{1}$ Referred to as Science Communication in the rest of this article.

${ }^{2}$ Referred to as JCOM in the rest of this article.
} 
Trends in science communication as a field of research

Research literature dealing with bibliographic data that characterises research outputs in the field of science communication is relatively scarce [e.g., Bucchi and Trench, 2014; Borchelt, 2012] and the existing analyses were in some cases not done broadly or systematically. The current study — attempting a broad and systematic bibliographical analysis - is the first one that goes back to the launch of the first journal dedicated to this field (1979) up to 2016, and is therefore a first step towards a more comprehensive view of trends in science communication research.

\section{Growth in research outputs}

It is well documented that research productivity in the field of science communication is on the rise. For example, Gascoigne et al. [2010] highlight that, in 2010, a Google search for the phrase "books on 'science communication" " yielded about $115000^{3}$ results, while a similar search for journal papers confirmed that science communication could be credited with a significant weight of scholarly enquiry and growth in research activity. Trench [2012] links this growth in science communication scholarship to the establishment of science communication courses and degree programmes at universities around the world that have stimulated research activity.

In their collection of formative papers in the field of science communication, Bucchi and Trench [2014] present two time frames: 37 publications were published in the 60 years before 1995, and 42 in the 20 years after that. The authors see this as reflecting an increased publishing activity in the later period [see Trench and Bucchi, 2015]. More systematic approaches document that, in the 1237 papers from 471 different journals explored in Borchelt's [2012] study, more than twice as many articles were published between 2005 and 2009, compared to the period 2000 to 2004 .

Bauer and Howard [2013] provide an interesting bibliography of publications in the journal Public Understanding of Science for the time frame 1992 - 2010. The authors highlight that, from 2009 onwards, the journal increased the number of issues per year, from four to six. Since 2012, this number jumped to eight issues per year - reflecting an ongoing growth in the number of papers expected to be suitable for publication. However, to the authors' knowledge, there were no similar bibliographies available for other main journals in the field. Similarly, the journal Science Communication expanded from four to six issues per year in 2012, which Hornig Priest [2012] attributes to a growing number of submissions resulting from the growth and stature of the field. In 2016, for the first time, JCOM published not four but six issues per year. ${ }^{4}$

Lastly, in his meta-analysis focusing on research on the media coverage of science, Schäfer [2012] also highlights that the number of published articles increased significantly in this field which represents a prominent secondary field of enquiry within the field of science communication.

\footnotetext{
${ }^{3}$ In February 2017, the same search yielded 657000 results. While this is indicative of a growth in the number of books that deal broadly with the topic of science communication, the increase in the number of results may also have been influenced by changes in the way online searches are optimised.

${ }^{4}$ It should be noted that two of them were special issues.
} 
Drawing from these findings, it is evident that the overall volume of research outputs in science communication has grown steadily in recent years. However, a broad and systematic, bibliographic overview of the trends in research productivity within this research field is still lacking.

\section{Patterns of authorship}

Patterns of authorship explore whether authors published individually or with co-authors, as well as how much of the overall research output is attributable to single authors.

In their anthology, Bucchi and Trench [2014] note that certain authors' names surfaced repeatedly when they surveyed the field to identify the most influential works. While recognising the influential roles and contributions of early advocates for science communication as an independent field of enquiry, Bucchi and Trench decide to include a maximum of two works by any one author. Similarly, Trench [2012] acknowledges the individual champions who established the first programmes to teach science communication at university level. However, Bucchi and Trench [2014] also highlight an increase in multi-authored and cross-country studies - reflecting collaborative trends towards increasing institutionalisation and internationalisation respectively [see also Trench and Bucchi, 2015].

The systematic approach followed in the current study aimed to provide additional evidence to support these findings and verify these trends.

\section{Geographical spread of authors' institutions}

Trench et al. [2014] highlight that the first large-scale international conferences on science communication in the early 1990s were mainly restricted to scholars from Western Europe and North America. However, more recent conferences of the Public Communication on Science and Technology [PCST] Network attracted contributions from more than 50 countries [Gascoigne et al., 2010; Trench et al., 2014].

Notwithstanding this evidence of growing global interest in the field, some countries continue to overshadow the contributions of others in terms of science communication research activity. Referring again to the anthology by Bucchi and Trench [2014], the USA and the UK jointly accounted for $60 \%$ of the total number of authors (including co-authors) when each author is assigned to a country by her/his institution. However, the authors list an equal representation of these two countries - a finding that is not supported by other researchers. In the study by Borchelt [2012] - mapping a decade of science communication outputs from 2000 to 2009 - the dominance of North America is more apparent. In this study, the USA accounted for 427 [34.5\%] of the 1237 articles included in the mapping exercise, while the UK accounted for 270 [21.8\%], followed by Canada [77, or 6.2\%] and Australia [51, or 4.1\%]. Jointly, these five countries contributed 825 papers $[66.7 \%]$ of the total, confirming the dominance of research contributions from Western, English-speaking countries. Similar findings emerge in Bauer and Howard's [2013] bibliography, in which two thirds of the research articles published in Public Understanding of Science between 1992 and 2010 originated from 
the USA, the UK, Canada, Australia and New Zealand. Only one sixth of the papers in this study were from Asia, Africa and Latin America.

Schäfer [2012] assesses which countries were analysed in research papers looking at the media representation of science. Also in this case, the finding is that the USA [37\%] and the UK [25\%] were analysed most often, with a general more intense focus on Europe, North America and Oceania. Schäfer's sample did not include any studies that analyse media coverage on the African continent.

The perceived need to provide a global overview of research contributions and theoretical developments in the field of science communication - going beyond journal publications - was the driving force behind "Science Communication in the World" [Schiele, Claessens and Shi, 2012a]. However, even in this book with the stated aim to reflect the global scope of the field, Africa is poorly represented, with only one of the 15 national overviews coming from Africa, while Europe and Asia are reflected in five contributions each.

It is generally assumed that the diversity of authors' nationalities increased significantly in recent years [Trench and Bucchi, 2015] and that this trend will continue. In this regard, Bauer and Howard [2013] identify a trend towards a wider range of countries represented in the journal Public Understanding of Science than before, adding that it was a key objective to achieve a more global representation of authors in future. A special 2015-issue of this journal focuses on "voices from other lands" - including Latin America, Africa and Asia - in an attempt to make room for a wider diversity of authors and countries. In her introduction to this issue, Massarani [2015] echoes concerns about the bias in science communication research literature towards Western, English-speaking countries, and she encourages the inclusion of different perspectives emanating from previously under-represented regions of the world. Similarly, in his introductory editorial as editor of Public Understanding of Science, Bucchi [2016] notes recent expansions and growing global interest in this field and emphasises the need for this journal to attract high-quality research contributions from diverse social and cultural contexts.

In her reflection on the first five years of JCOM, Weitkamp [2016] emphasises the importance for this journal to provide a platform for geographically diverse voices and, therefore, the need to attract contributions from around the world that would reflect the global field of science communication. Weitkamp lists 19 countries where corresponding authors that published in the journal during 2015 were based. While this list represented a diverse range of authors and contexts for science communication research, the northern hemisphere dominated (12 of the 19 countries) and contributions from Africa and Asia were noticeably low (there was only one country from each of these continents).

Drawing from these findings, it can well be assumed that authors of research into science communication are predominantly from Western, English-speaking countries, but that this situation may be changing. What is missing, is an updated, comprehensive and broad overview of the geographical spread of authors in the field and associated trends over time. 
The gender diversity of eminent scholars in the field - as reflected in the anthology presented by Bucchi and Trench [2014] — improved between the two selected time frames in which the selected works were grouped: "women account for one in five authors up to 1995, and nearly one in three for the period since then" [Trench and Bucchi, 2015, p. 4]. This shows that the situation is improving, but that a dominance of male authors persists in science communication research. These findings need to be verified by additional bibliographic and temporal analyses.

Current study and research questions
Available evidence to date indicates disparities in the field of science communication research outputs in favour of [mainly] male authors from Western, English-speaking countries. However, it is not clear how current trends increasing research outputs and shifting authorship patterns - are beginning to correct some of these imbalances and may, therefore, rectify these distortions over time.

Existing literature provides a comprehensive overview of research activities in science communication, but does not analyse bibliographic trends comprehensively and the literature itself has important limitations. Bucchi and Trench's [2014] anthology includes 79 publications only. Borchelt's [2012] study focuses exclusively on a ten-year period [2000-2009] and excludes research on formal science education and teaching, and health communication. Schäfer [2012] only considers research on the representation of science in the media. The bibliography by Bauer and Howard [2013] is restricted to one journal, Public Understanding of Science.

By comparison, the present study aimed to analyse research in science communication from a broad bibliographic perspective, covering the entire publication record of the three research journals that are dedicated to the field. Our study focused on peer-reviewed journal articles, a format that is recognised as highly relevant for professional communication [Bucchi and Trench, 2014]. We selected to focus on the three English-language journals that are dedicated to the field: Science Communication, Public Understanding of Science, and JCOM. Our analysis covered a full sample of all peer-reviewed research published in these three journals from the first issue of each of these three journals up to the end of 2016. We assessed the volume of research outputs, patterns in authorship, the geographical spread and the gender of the authors. An additional advantage of the current study is that - given the contested definition of science communication [Burns, O'Connor and Stocklmayer, 2003; Trench and Bucchi, 2010] — we opted not to use pre-defined keywords [Borchelt, 2012; Schäfer, 2012] to identify relevant articles in the field. Instead, our analysis included all research outputs published in the three peer-reviewed journals that we have selected for our study.

Since this bibliographic paper was interested in a broad view of research outputs, the authors and authorship patterns, the countries of authors' institutions and the gender of authors that publish in the three main journals of the field, the following research questions $[R Q]$ guided the analysis.

While we can assume that there is a growth of research papers over time, we lack data on when and to what extent the research output has grown. That is why we 
asked (RQ1): How does the research output of the three main journals of the field of science communication change over time?

We can also assume that patterns of authorship have changed over time. What we do not know in detail, is - when looking at the authors of the research papers (RQ2): Can we identify trends of institutionalisation and internationalisation?

For the geographical spread of authors' institutions, the literature reflects the dominance of Western, English-speaking countries. However, with changing patterns of authorship this dominance might have become less over time. Therefore, we asked (RQ3): How does the geographical spread of authors' institutions change over time?

Regarding the gender of authors, we expect a dominance of male authors, along with evidence of more female authors over time. That is why we asked (RQ4): How does the gender (im)balance in authorship change over time?

This approach was deemed to be useful to gain a comprehensive perspective on the dynamics of science communication as a field of research, and particularly to identify research gaps and challenges.

In the present study, Science Communication, Public Understanding of Science and JCOM were defined as the three main journals in the field of science communication. There were four primary reasons for this specific selection:

1. The chosen journals are, according to Borchelt's study [2012], among the five leading journals in which articles about science communication are published. Public Understanding of Science and Science Communication take the leading positions. Borchelt [2012] also lists Risk Analysis and the Journal of Risk Research as top journals, but - unlike the three journals we have selected these journals do not explicitly define science communication as one of their key focus areas on their websites, and were consequently excluded.

2. If we instead would work with a list of keywords to identify articles dealing with science communication and identify the articles via citation indexes [e.g., the Social Sciences Citation Index as used by Schäfer [2012], see also Borchelt [2012]] regardless of the journals in which they have been published, then this list of keywords would already be a limitation and it would be necessary to define the field. As highlighted earlier, the problem is that definitions of science communication are still contested [Bucchi and Trench, 2014; Burns, O'Connor and Stocklmayer, 2003]. For the same reason, we also did not include books.

3. In addition, both Science Communication and Public Understanding of Science feature dominantly in the anthology of Bucchi and Trench [2014] that aims to be a collection of foundational and cutting-edge scholarship in the field of public communication of science. 
4. The third journal that we investigated in our study - JCOM - was included because it is the first and only open-access journal devoted to the field of science communication, and the journal has been well established for more than a decade.

For the three selected journals, all articles published up until the end of the year 2016 were downloaded from the archives of their respective websites. However, not the entire journal content was included in the analysis. Since the focus of this paper was on theoretical and empirical research papers, we only included empirical articles, theoretical and practical perspectives, and research notes. We excluded journal content that we perceived as not being peer-reviewed, such as editorials (also launch perspectives), introductions and responses within special issues, essays, reports, commentaries and (book/conference) reviews, correspondences, errata, memorials, excerpts, previews and news, or author guidelines.

Each downloaded article counted as a new coding unit in this investigation. There was no random selection of articles; the full sample was analysed. Science Communication was established in 1979, ${ }^{5}$ Public Understanding of Science in 1992, and JCOM in 2002. For Science Communication and Public Understanding of Science we only included published articles (and not the earlier online versions of the same articles, or online-first articles that have not yet been printed by the end of 2016). For JCOM - as an online journal — we had no other choice than to include online articles only.

The total numbers of outputs per journal were biased in the sense that the three journals were launched at different times.

\section{Data analysis}

Although the current investigation was only interested in the formal categories of a content analysis, and we refer to this as a bibliographical analysis, we nevertheless created a small, but comprehensive codebook to guide and support our systematic analysis.

To answer RQ1, the authors of this paper extracted the name of the journal as well as the year of publication [see Schäfer, 2012]. To answer RQ2, one variable assessed the total number of authors of the paper and a second variable the detailed name(s) of the author(s) [see also Borchelt, 2012]. To find an answer to RQ3, we assessed the countries of the authors' institutions [see also Borchelt, 2012]. Hence, in this study, the geographical spread of authors was assessed according to a country assigned to each author based on the physical location of the institutions where they were affiliated at the time of publication ${ }^{6}$ [Trench and Bucchi, 2015]. In addition, a variable assessed if — in the case of multi-authorship - authors' institutions were based in the same or different countries. This variable was part of RQ2. Lastly, and to answer RQ4, we extracted the gender of the author(s). Whenever this was not evident from the authors' names, we consulted the biographies published within

\footnotetext{
${ }^{5}$ Science Communication is named like this ever since volume 16 in 1994; before that, the title of the journal was Knowledge: Creation, Diffusion, Utilization.

${ }^{6}$ Where an author provided more than one affiliation, the institutional affiliation listed first was used.
} 


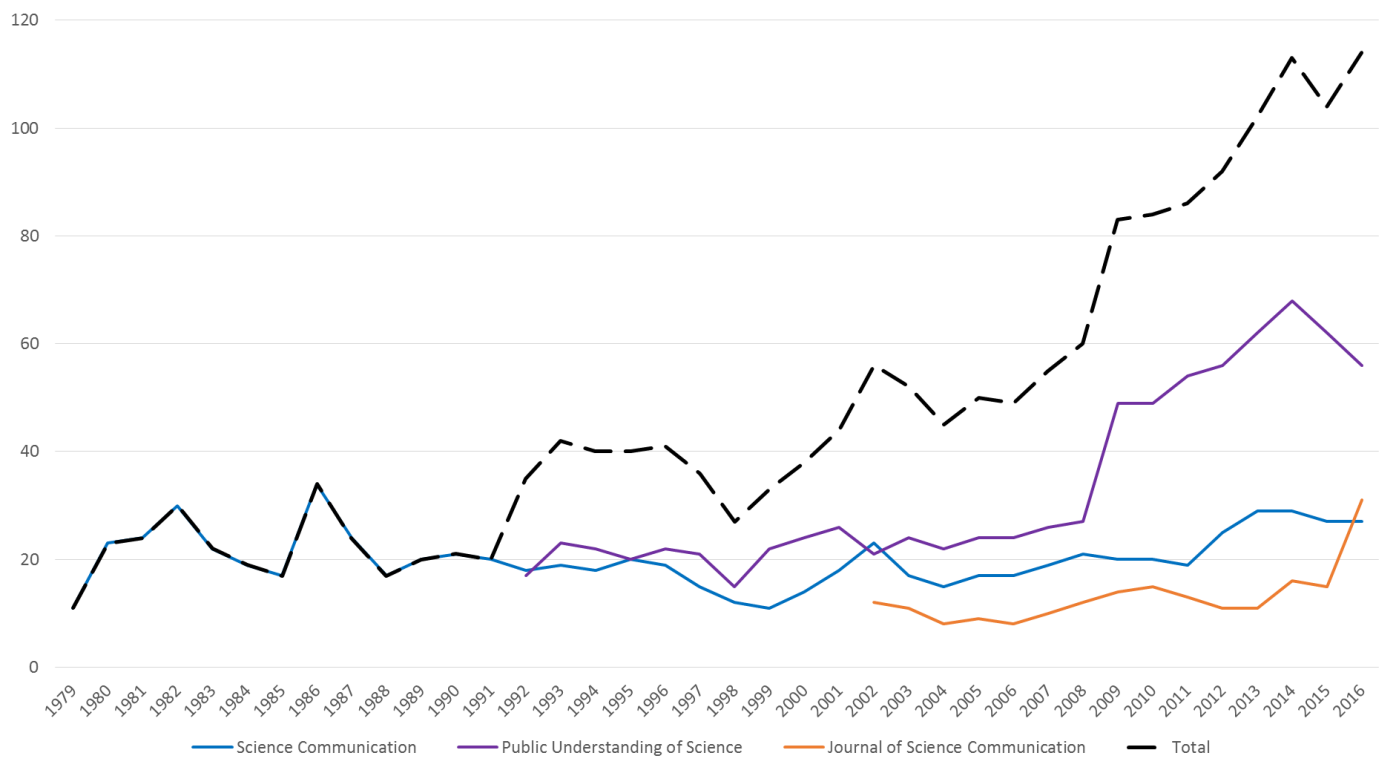

Figure 1. Articles per year, per journal.

the article and searched for information online to verify the gender of the person(s) in question.

All information that was mostly directly retrieved from the journal paper were entered into SPSS. To answer the RQs, the following results section will look predominantly into descriptive findings over time.

To answer RQ1, the research output (or volume) over time was investigated. Of the total number of articles $(n=1803)$ published, $771(42.8 \%)$ were published in Science Communication, 836 (46.4\%) in Public Understanding of Science and 196 (10.9\%) in JCOM. As can be seen in Figure 1, Public Understanding of Science not only published the most articles, but also increased its output over time. Science Communication displayed a relatively stable output rate, while JCOM showed a recent increase. The combined output of the three journals increased significantly since 1991 and again since 1998, and has increased sharply once more since 2004.

To answer RQ2, we looked at authorship patterns. Most articles had a single author $(n=848 ; 47 \%)$, or two authors $(n=487 ; 27 \%)$. Articles with three authors were less common $(n=257 ; 14.3 \%)$, with comparatively few articles that had four authors $(n=117 ; 6.5 \%)$, five authors $(n=48 ; 2.7 \%)$, six authors $(n=26 ; 1.4 \%)$ or more than six authors $(n=15 ; 0.9 \%){ }^{7}$

In the 1803 articles published in the three journals since 1979, the name of an author was mentioned 3593 times. After elimination of duplicates, a total of 2680 unique authors were mentioned. ${ }^{8}$ In total, 28 researchers authored six or more

\footnotetext{
${ }^{7}$ There were five articles for which the number of authors was unclear because teams, study groups, or organizations were displayed as authors.

${ }^{8}$ Both the AVSA and the ESConet Team, as well as the International Study Group on Potential Values and Benefits of Research, and the Wellcome Trust were excluded from the analyses because they could not be counted as single authors.
} 
articles, with one author reaching the highest number: 14 articles in total. In our study, 30 authors published five articles, 51 authors published four articles, 87 authors published three articles, and 279 authors published two articles. Most authors $(n=2205)$ published one paper only.

The findings show that for articles with multiple authors $(n=955)$, authors' home institutions were based in different countries in only 16.1 per cent $(n=154)$ of cases. Hence, for the vast majority of articles with more than one author, the authors were from the same country $(n=801 ; 83.9 \%)$. However, for multi-author papers the number of authors representing institutions in different countries increased significantly over time $(\beta=0.154 ; p<0.001)$, confirming a trend towards more internationalisation. Furthermore, the data also supported that, over time, there was a trend towards more multi-authored papers $(\beta=0.288 ; p<0.001)$. This can be seen as confirming a trend towards more collaboration (as part of an increasing institutionalisation).

To answer RQ3, we counted 57 different countries mentioned as the institutional base for authors in this study. The USA was by far the country in which most of the authors' institutions were based ${ }^{9}$ (see Table 1). The UK ranked second with far fewer authors in Canada, the Netherlands, Australia, and Germany. Japan, in the ninth place, topped the list in terms of Asian countries where authors were based, while Brazil (ranked 10 $0^{\text {th }}$ ) performed best on the list of developing countries. The world map of science communication (Figure 2) - based on this data - shows that most researchers worked for institutions based in North America and Europe, while fewer of them worked for institutions in Asian and South American countries, and even fewer in African countries and the Middle East. South Africa took a leading position when it came to African countries, being the global number 29.

If we consider trends in the geographical location of authors' institutions over time (Figure 3), it becomes clear that USA-based authors have published considerably and consistently more than authors from any other country, and that this dominance has increased sharply since 2012. The number of authors from UK-based institutions has increased steadily since 1992. More recently, Germany took the $3^{\text {rd }}$ place in terms of institutional affiliations reflected in these three journals. Brazil, South Africa and Singapore are included as examples of countries with noticeable recent mentions as countries where authors are based.

The representation of the countries with $50+$ mentions as the location of authors' institutions was interestingly different between the three journals considered in this study (Table 2). Patterns shown by countries such as Australia, Canada and Germany can be explained by the higher output of Public Understanding of Science. However, the dominance of the USA was particularly apparent in Science Communication and most certainly related to the early years of the journal. In Public Understanding of Science, the UK was even more often listed as the geographical base of an author's institution than the USA. Authors based in Brazilian and Italian institutions published comparatively often in JCOM.

\footnotetext{
${ }^{9}$ The top six authors - in terms of their combined output in the three journals - were all based in the USA.
} 
Table 1. Top ten countries according to authors' institutions.

\begin{tabular}{|lc|}
\hline Country & Counts [per cent] \\
\hline USA & $1401[39.0 \%]$ \\
UK & $569[15.8 \%]$ \\
Canada & $192[5.3 \%]$ \\
Netherlands & $164[4.6 \%]$ \\
Australia & $154[4.3 \%]$ \\
Germany & $128[3.6 \%]$ \\
Spain & $90[2.5 \%]$ \\
Italy & $89[2.5 \%]$ \\
Japan & $63[1.8 \%]$ \\
Brazil & $56[1.6 \%]$ \\
\hline
\end{tabular}

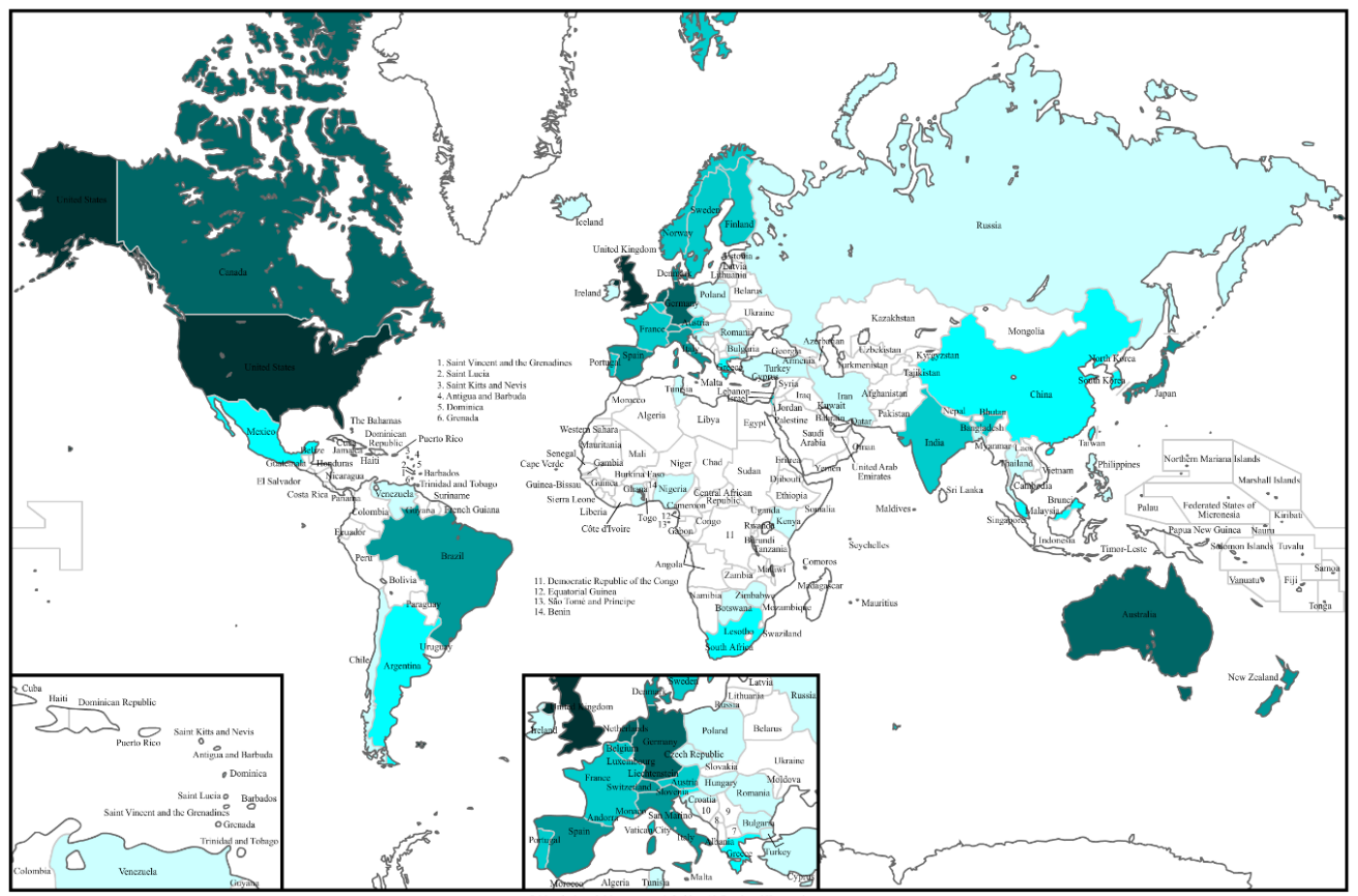

Figure 2. A world map of science communication research. Note: The intensity of the colour is an indication of the publication output, with lighter shades representing fewer publications. The darkest shades represent the USA (1 401 counts) and the UK (569 counts), with the next five progressively lighter shades representing 100-200 counts, 50-99 counts, $25-49$ counts, $10-24$ counts, and 1-9 counts respectively.

To answer RQ4 (the gender balance of authors), of the 2680 authors, $54.9 \%$ ( $n=1471)$ were identified as male, and $45.1 \%$ as female $(n=1209)$. Looking at developments over time (Figure 4), we can see that in the early years, authors were predominantly male. Recently, however, female authors became more dominant than males. Furthermore, our results showed that female authors contributed to multi-author articles comparatively more often $(M=3.12 ; S D=1.944)$ than their male counterparts $(M=2.62 ; S D=1.641 ; t=8.070 ; p<0.001)$. 


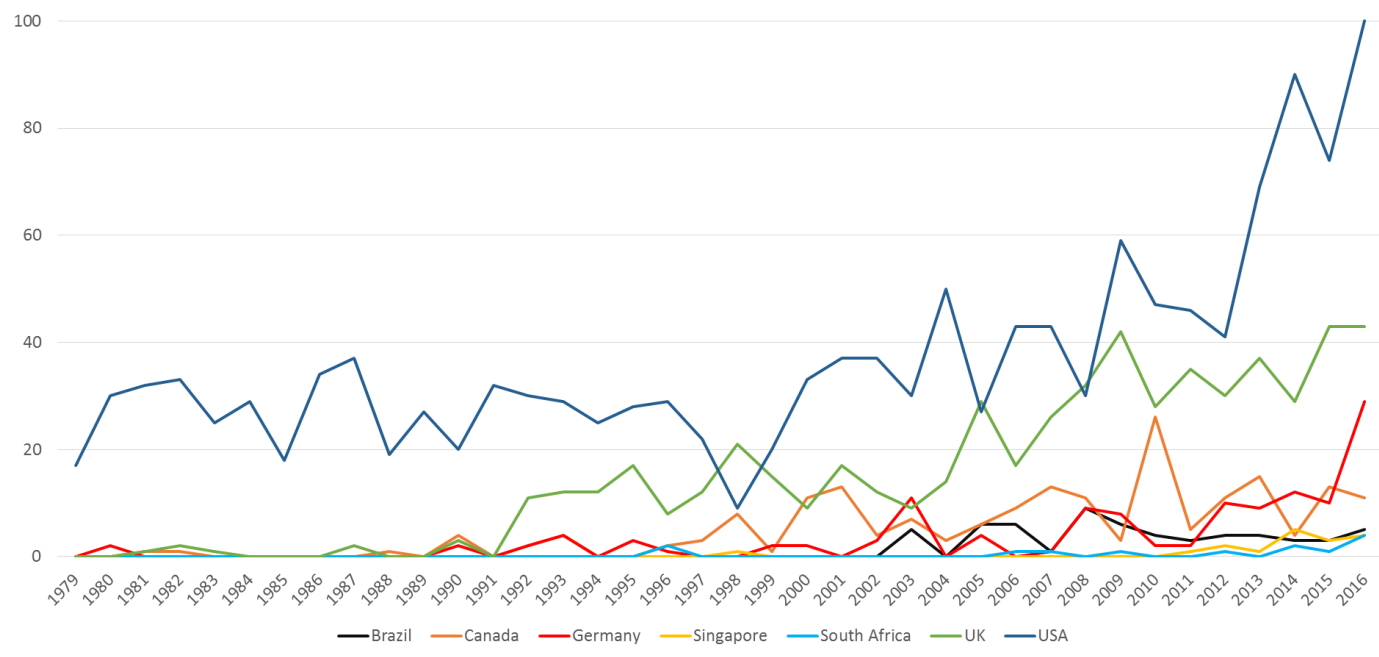

Figure 3. Selected countries of authors' institutions over time.

Table 2. Countries of authors' institutions as represented in the journals (counts [per cent]).

\begin{tabular}{|lccc|}
\hline Countries & $\begin{array}{c}\text { Science } \\
\text { Communication }\end{array}$ & $\begin{array}{c}\text { Public Understanding } \\
\text { of Science }\end{array}$ & $\begin{array}{c}\text { Journal of Science } \\
\text { Communication }\end{array}$ \\
\hline Australia & $42[27.3 \%]$ & $90[58.4 \%]$ & $22[14.3 \%]$ \\
Brazil & $2[3.4 \%]$ & $9[15.3 \%]$ & $48[81.4 \%]$ \\
Canada & $66[34.4 \%]$ & $109[56.8 \%]$ & $17[8.9 \%]$ \\
Denmark & $7[13.0 \%]$ & $31[57.4 \%]$ & $16[29.6 \%]$ \\
Germany & $39[30.5 \%]$ & $78[60.9 \%]$ & $11[8.6 \%]$ \\
Italy & $2[2.2 \%]$ & $24[27.0 \%]$ & $63[70.8 \%]$ \\
Japan & $2[3.2 \%]$ & $31[49.2 \%]$ & $30[47.6 \%]$ \\
The Netherlands & $63[38.4 \%]$ & $81[49.4 \%]$ & $20[12.2 \%]$ \\
New Zealand & $19[35.5 \%]$ & $27[51.9 \%]$ & $6[11.5 \%]$ \\
Spain & $17[18.9 \%]$ & $59[65.6 \%]$ & $14[15.6 \%]$ \\
Switzerland & $15[27.8 \%]$ & $34[63.0 \%]$ & $5[9.3 \%]$ \\
UK & $88[15.5 \%]$ & $428[75.2 \%]$ & $53[9.3 \%]$ \\
USA & $925[66 \%]$ & $421[30.0 \%]$ & $55[3.9 \%]$ \\
\hline
\end{tabular}

Looking at the countries that have yielded $50+$ articles, it is interesting to note that some countries seem more gender-balanced than others (see Table 3). Countries such as Australia, Canada, Japan, and Switzerland presented a very balanced picture in terms of the female vs. male author ratio. Brazil was the only country with significantly more female than male authors, while Denmark, Spain, Germany and the Netherlands were represented by more male than female authors. Men also published more than women in the case of authors from the UK and the USA, but the gender difference was less apparent when compared to the countries mentioned before. 


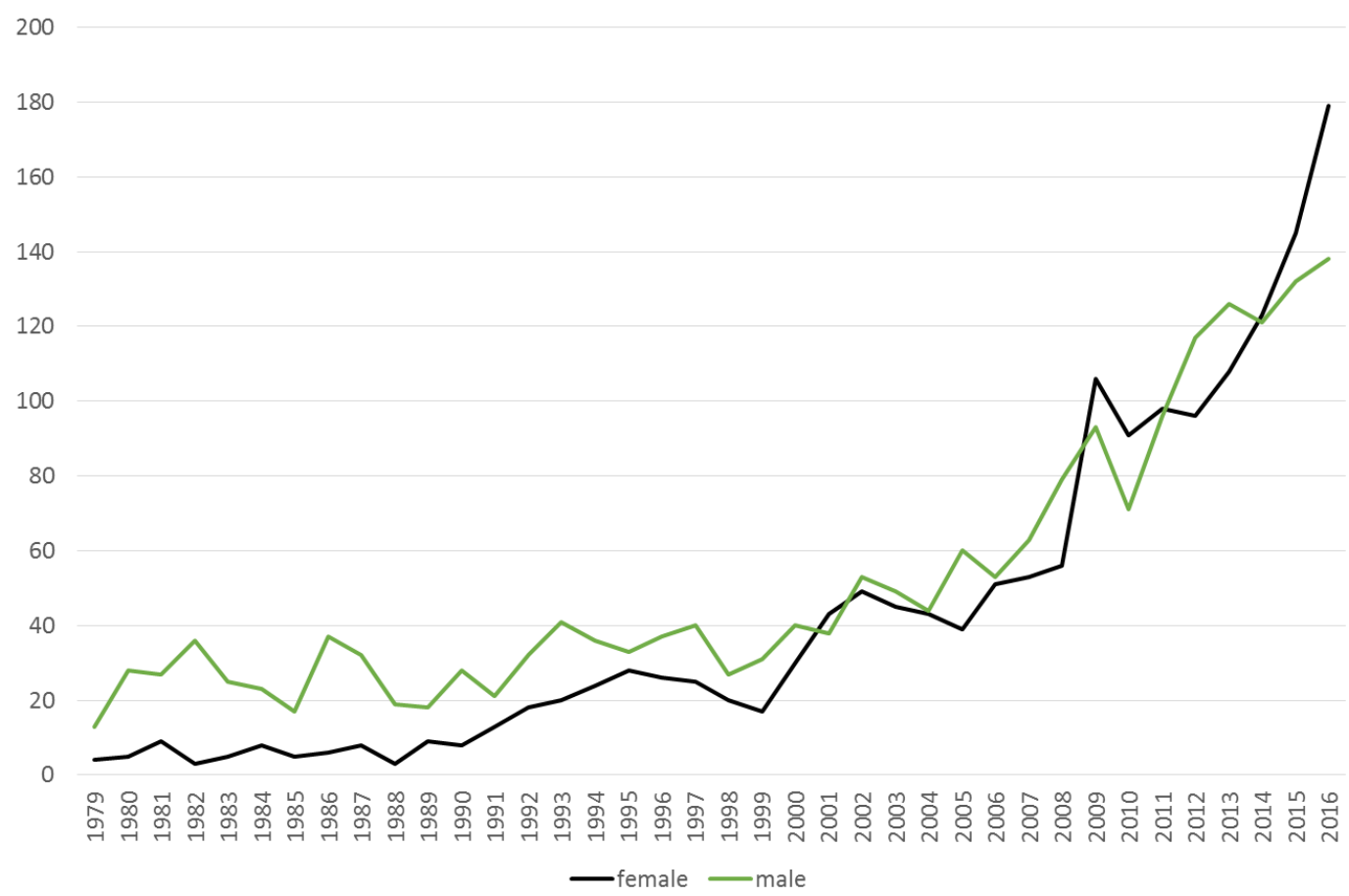

Figure 4. Gender of authors over time.

Summary and discussion
Our findings confirm that science communication is maturing as a field of scholarly activity, as shown by a steady and significant increase in the number of peer-reviewed research outputs published by the three main journals in the field over the last $30+$ years. This verifies the increase in science communication research noted earlier by Gascoigne et al. [2010], Trench and Bucchi [2015], Borchelt [2012] and Bauer and Howard [2013]. Furthermore, the fact that both of the historically established journals increased the number of issues published per year, and that more recently a new, open-access journal has been established successfully, demonstrate a growing interest on the part of researchers and a positive trend in high-quality research activity in the field. Science communication research seems to follow the overall trend in growing output in scientific research in general, as referred to by Bauer and Howard [2013].

While it is encouraging that a total of 2680 unique authors contributed to published research in our study, it is less reassuring that the vast majority of them $(82.3 \%)$ published only once in the main journals of the field. This could mean that many individuals were involved in science communication research only fleetingly, and that the sustained research outputs over time originate from a much smaller number of scholars. Furthermore, the fact that only 28 researchers published six or more articles (over the entire period since 1979 and in all three journals combined) is perhaps an indication that there are still relatively few research leaders in the field - which is to be expected in an emerging and multi-disciplinary field of research [Gascoigne et al., 2010] and can possibly be attributed to the formative role of the early advocates and champions in the field referred to by Trench [2012] and Trench and Bucchi [2015]. In terms of authorship patterns, it is clear that articles written by one or two authors are still the norm (representing $74 \%$ of the total output), while it is rare to find large research teams presenting joint papers for 
Table 3. Gender ratios of authors' institutional home base according to country.

\begin{tabular}{|lccc|}
\hline Country & Female & Male & Female: Male ratio \\
\hline Australia & $78[50.6 \%]$ & $76[49.4 \%]$ & 1.02 \\
Brazil & $35[59.3 \%]$ & $24[40.7 \%]$ & 1.46 \\
Canada & $92[47.9 \%]$ & $100[52.1 \%]$ & 0.92 \\
Denmark & $19[35.2 \%]$ & $35[64.8 \%]$ & 0.54 \\
Germany & $42[32.8 \%]$ & $86[67.2 \%]$ & 0.49 \\
Italy & $41[46.1 \%]$ & $48[53.9 \%]$ & 0.85 \\
Japan & $31[49.2 \%]$ & $32[50.8 \%]$ & 0.97 \\
The Netherlands & $59[36.0 \%]$ & $105[64.0 \%]$ & 0.56 \\
New Zealand & $28[53.8 \%]$ & $24[46.2 \%]$ & 1.17 \\
Spain & $33[36.7 \%]$ & $57[63.3 \%]$ & 0.58 \\
Switzerland & $27[50.0 \%]$ & $27[50.0 \%]$ & 1.00 \\
UK & $266[46.7 \%]$ & $303[53.3 \%]$ & 0.88 \\
USA & $628[44.8 \%]$ & $773[55.2 \%]$ & 0.81 \\
\hline
\end{tabular}

publication (only $5 \%$ of all research outputs were authored by five or more authors).

The positive shift towards institutional collaboration (as demonstrated by a growth in multi-authored papers) and internationalisation (a growth in involvement of different countries in multi-authored papers) bode well for the future of the field where many scholars have emphasised the importance of involving researchers from around the world and reflecting the truly global nature of science communication research [Massarani, 2015; Trench and Bucchi, 2015]. However, our "world map of science communication research" clearly elucidates the need to attract more research contributions from the southern hemisphere in general, but particularly the imperative to boost science communication research in Africa, Asia and the Middle East [see also Bauer and Howard, 2013]. This is where gaps and challenges in the field of science communication research lie.

Lastly, the trend towards more female authors enhances the gender diversity of the field [see also Trench and Bucchi, 2015]. However, the current study was only a starting point towards providing a comprehensive picture of trends in science communication research. In this study, we were only interested in bibliographic data, and the study was limited to three journals only. While the inclusion of more journals would provide a more comprehensive analysis, it is an open question whether this would necessarily alter any of the patterns and trends observed by focusing exclusively on the three journals dedicated to research in the field of science communication.

Furthermore, the current study included only English-language journals, acknowledging that English is the lingua franca of modern science [Bauer and Howard, 2013], but recognising that science communication research is also published in other languages (for example the Japanese Journal of Science Communication) and in regional contexts (such as the English-language Indian Journal of Science Communication). For China, Xu, Huang and Wu [2015] highlight that very few Chinese scholars publish in international journals - such as the three 
selected for the present study — but rather in local academic journals. We also acknowledge that quantity (volume of articles published) is not necessarily a measure of impact and that the current study did not compare the acceptance rates or impact factors of the journals under consideration, nor did we assess the quality of the published research outputs alt- or scientometrically.

While there were specific reasons for these limitations, a follow-up study could include more sources (including books and grey literature), as well as extend the content focus on the topics of research, the scientific fields in which the research is embedded and the methodologies used. Such an approach would go further towards identifying research gaps and challenges, as well as research priorities [for an attempt, see Bauer and Howard, 2012; or Smallman, 2016]. For instance, Schäfer [2012] is able to show that studies interested in media representation of science are biased towards covering natural sciences in print media. Furthermore, Trench and Bucchi [2010] comment that science communication is under-theorised. This claim deserves further validation.

Recommendations for diversity and developing countries
From time to time, scholarly journals publish special issues focusing on a particular topic in science communication - reflecting on current research and typically also looking forward to future research challenges. All three journals included in our study regularly published such special issues. Deviating from this pattern of topic-based special issues, Public Understanding of Science also made an effort to increase the diversity of authors published in this journal by creating a special issue — in 2015 — with the theme "voices from other lands", featuring authors from Latin America, Africa and Asia. It is debatable, however, whether it is the role of scholarly journals to address gaps and imbalances in the scholarly literature, or whether this is a task for the research community and funders of science communication research.

Arguably, instead of calling for research papers from developing country authors, a more effective way of stimulating diversity in research authorship would be to encourage collaborative research that would include researchers in developing countries from the outset of multi-country research projects. For example, if research funders provided incentives for researchers from the developed world to include partners from developing countries in their research designs, this is likely to result in multi-authored papers which would include developing country authors.

To give an illustrative example of why developing countries are underrepresented in scholarly journals, we conclude this paper with an extended view of the African continent. Our study yielded only 20 papers from Africa, representing only $1.1 \%$ of the total research output under investigation. According to the institutional affiliation of the corresponding author, 12 of these papers came from South Africa, while the rest came from Botswana $(n=2)$, Ghana $(n=1)$, Kenya $(n=1)$, Nigeria $(n=2)$, Tunisia $(n=1)$ and Zimbabwe $(n=1)$. Jointly, these 20 papers had 19 Africa-affiliated authors, which is only $0.007 \%$ of the total number of unique authors counted in this study. Bauer and Howard [2013, p. 10] noted the lack of critical mass in Africa in terms of contributing to science communication research, but suggested that "as with so many things, here the future is likely to be in Africa". 
However, it is important to take note of the particular science communication challenges that are prevalent in developing countries in general, and in some African countries in particular, that may restrict science communication research outputs coming from this continent. Historically, science was suppressed in Africa during colonial times, similarly to the way it was kept away from Brazilian citizens during the Portuguese occupation, as described by Massarani and De Castro Moreira [2016]. Only the colonial powers had access to scientific knowledge thanks to their education and links with Europe, and their scientific interests were focused on their own needs in fields such as navigation, astronomy, cartography, mining, plantations, and the use of local plants, as well as the collection of plant and animal specimens that were sent back to Europe. In South Africa, the majority of the people continued to be isolated from science during the Apartheid regime (which lasted up until 1994) - a period when science was equated with strategic advantage and the communication of scientific ideas was suppressed [Dubow, 2006].

Furthermore, the cultural and language barriers that are prevalent in many developing countries present specific challenges for public science engagement [Fish et al., 2016]. Clayton and Joubert [2012] explain the barriers that science journalists in Africa face in terms of getting access to science news. Bakyawa et al. [2013] demonstrate how a lack of funding and infrastructure impedes health communication in Uganda. Appiah et al. [2015] reveal the lack of institutional support and training that impedes science journalism in Ghana. Ndlovu, Joubert and Boshoff [2016] illustrate how the lack of incentives and the censoring of politically sensitive findings limit public communication of research findings in Zimbabwe. Massarani and De Castro Moreira [2016] discuss the challenges of effectively communicating science in a very large country with widely dispersed rural populations - a situation that is relevant in many African countries.

Hin and Subramaniam [2014] further explicate some of the social and structural barriers that typically constrain public science communication in developing countries. In addition to perceived clashes between a modern science culture and indigenous knowledge (or native culture), science communication is hampered by a lack of institutional mechanisms such as science academies, scientific societies suitable for promoting public science engagement, while inadequacies in science journalism expertise and platforms remain a concern. The authors also highlight the challenges of promoting science to communities that are plagued by poverty, famine, corruption, violence and political instability.

In this context, it is vital to note that, in developing world contexts, public communication of science and technology has to resonate with societal needs and priorities and demonstrate the relevance of science in public health, food security, shelter and safety. Fayard, Catapano and Lewenstein [2004] point out that views from the developed world about what constitutes a good science communication programme may not be relevant in the developing world, where people's priorities are very different and where they often face a complex mix of infrastructural, economic, educational and social barriers in terms of accessing scientific information. At the same time, the life challenges that many Africans face on a daily basis necessitates improved understanding of science and better engagement between scientists and communities. For example, Nyirenda et al. [2016] highlight how misconceptions about health sciences hampers the implementation of research 
in Malawi, where an exceptionally high burden of disease affects the population of whom the vast majority lives in rural areas.

There is no doubt that the African continent presents a rich and multi-faceted study terrain for science communication scholars and that there are huge opportunities for cross-country collaborations between established researchers in other parts of the world and African counterparts. However, for Africa to make a more meaningful contribution to research in this field, a significant and concerted effort to stimulate research skills, interest and activity will be required.

Acknowledgments

\section{References}

Appiah, B., Gastel, B., Burdine, J. N. and Russell, L. H. (2015). 'Science reporting in Accra, Ghana: Sources, barriers and motivational factors'. Public Understanding of Science 24 (1), pp. 23-37. DOI: 10.1177/0963662514547478.

Bakyawa, J., Devlin, M., Serwadda, D. and IJsselmuiden, C. (2013). 'Implementing a health research communication program in a low resource country: Experience from Uganda's Makerere University School of Public'. Scholarly and Research Communication 4 (2). DOI: $10.22230 /$ src. 2013v4n2a103.

Bauer, M. W. and Howard, S. (2012). 'Public Understanding of Science - a peer-review journal for turbulent times'. Public Understanding of Science 21 (3), pp. 258-267. DOI: 10.1177/0963662512443407.

- (2013). Public Understanding of Science: compiled bibliography, 1992-2011. London, U.K.: Sage.

Borchelt, R. (2012). The Science Communication Research Literature Mapping Project. Plenary paper presented at the $12^{\text {th }}$ International Science and Technology Conference. URL: http://www. slideshare net/OPARC1/firenze-phd-slides.

Bucchi, M. (2016). 'Editorial'. Public Understanding of Science 25 (3), pp. 264-268. DOI: $10.1177 / 0963662516634497$.

Bucchi, M. and Trench, B., eds. (2014). Routledge Handbook of Public Communication of Science and Technology. 2nd ed. London, U.K. and New York, U.S.A.: Routledge. URL: https ://www . routledge .com/Routledge-Handbo ok-of-Public-Communication-of-Science-and-Technology-Second/BucchiTrench/p/book/9780415834612.

Burns, T. W., O'Connor, D. J. and Stocklmayer, S. M. (2003). 'Science communication: a contemporary definition'. Public Understanding of Science 12 (2), pp. 183-202. DOI: 10.1177/09636625030122004.

Clayton, J. and Joubert, M. (2012). The Need for an African Science News Service. Prepared on behalf of SciDev.Net for the UK National Commission of UNESCO. URL: http://www.southernscience.co.za/downloads/african_news_service _need.pdf. 
Dubow, S. (2006). A commonwealth of knowledge: science, sensibility and white South Africa 1820-2000. New York, U.S.A.: Oxford University Press.

Fayard, P., Catapano, P. and Lewenstein, B. (2004). 'The International Public Communication of Science and Technology'. Quark April/June (32), pp. 63-69.

Fish, D., Allie, S., Pelaez, N. and Anderson, T. (2016). 'A cross-cultural comparison of high school students' responses to a science centre show on the physics of sound in South Africa'. Public Understanding of Science, p. 0963662516642725. DOI: $10.1177 / 0963662516642725$. PMID: 27117487.

Gascoigne, T., Cheng, D., Claessens, M., Metcalfe, J., Schiele, B. and Shi, S. (2010). 'Is science communication its own field?' JCOM 9 (3), C04.

Hin, L. and Subramaniam, R. (2014). 'Challenges Facing Developing Countries in Communicating Science to the Public'. In: Communicating Science to the Public: Opportunities and challenges for the Asia-Pacific region. Ed. by L. Hin and R. Subramaniam. Dordrecht, Netherlands: Springer, pp. 213-222. DOI: $10.1007 / 978-94-017-9097-0 \_13$.

Hornig Priest, S. (2007). 'Science Communication: From Your New Editor'. Science Communication 29 (2), pp. 145-146. DOI: 10.1177/1075547007309214.

- (2010). Encyclopedia of Science and Technology Communication. London, U.K.: SAGE Publications.

- (2012). 'Editor's Note'. Science Communication 34 (1), pp. 3-4. DOI: $10.1177 / 1075547011432805$.

Massarani, L. (2015). 'Voices from other lands'. Public Understanding of Science 24 (1), pp. 2-5. DOI: $10.1177 / 0963662514563888$.

Massarani, L. and De Castro Moreira, I. (2016). 'Science communication in Brazil: A historical review and considerations about the current situation'. Anais da Academia Brasileira de Ciências 88 (3), pp. 1577-1595. DOI: $10.1590 / 0001-3765201620150338$.

Ndlovu, H., Joubert, M. and Boshoff, N. (2016). 'Public science communication in Africa: views and practices of academics at the National University of Science and Technology in Zimbabwe'. JCOM 15 (6), A05. URL: https://jcom.sissa.it/archive/15/06/JC0M_1506_2016_A05.

Nyirenda, D., Makawa, T. C., Chapita, G., Mdalla, C., Nkolokosa, M., Obyrne, T., Heyderman, R. and Desmond, N. (2016). 'Public engagement in Malawi through a health-talk radio programme 'Umoyo nkukambirana': A mixed-methods evaluation'. Public Understanding of Science. DOI: $10.1177 / 0963662516656110$.

Schäfer, M. (2012). 'Taking stock: A meta-analysis of studies on the media's coverage of science'. Public Understanding Science 21 (6), pp. 650-663. DOI: $10.1177 / 0963662510387559$.

Schiele, B., Claessens, M. and Shi, S. (2012a). 'Introduction'. In: Science Communication in the World. Ed. by B. Schiele, M. Claessens and S. Shi. Dordrecht, Netherlands: Springer, pp. xxiii-xxv. DOI: $10.1007 / 978-94-007-4279-6$.

- eds. (2012b). Science Communication in the World. Dordrecht, Netherlands: Springer. DOI: 10.1007/978-94-007-4279-6.

Smallman, M. (2016). 'Public Understanding of Science in turbulent times III: Deficit to dialogue, champions to critics'. Public Understanding of Science 25 (2), pp. 186-197. DOI: 10.1177/0963662514549141. 
Trench, B., Bucchi, M., Amin, L., Cakmackci, G., Falade, B., Olesk, A. and Polino, C. (2014). 'Global spread of science communication: institutions and practices across continents'. In: Routledge Handbook of Public Communication of Science and Technology. Ed. by M. Bucchi and B. Trench. 2nd ed. London, U.K. and New York, U.S.A.: Routledge, pp. 214-230. URL: https: //www . routledge.c om/Routledge-Handbook-of-Public-Communication-of-Science-and-Techno logy-Second/Bucchi-Trench/p/book/9780415834612.

Trench, B. (2012). 'Vital and Vulnerable: Science Communication as a University Subject'. In: Science Communication in the World. Ed. by B. Schiele, M. Claessens and S. Shi. Dordrecht, Netherlands: Springer, pp. 241-257. DOI: $10.1007 / 978-94-007-4279-6 \_16$.

Trench, B. and Bucchi, M. (2010). 'Science communication, an emerging discipline'. JCOM 09 (03), C03. URL: http://jcom.sissa.it/archive/09/03/Jcom0903\%282 010\%29C01/Jcom0903\%282010\%29C03.

- (2015). 'Science communication research over 50 years: patterns and trends'. Paper presented at 'Science and You' Conference.

URL: https://www . academia.edu/14286143/Science_communication_researc h_over_50_years_patterns_and_trends.

Weitkamp, E. (2016). 'Five years of JCOM — inclusive, comprehensive or could we do better?' JCOM 15 (4), E.

Xu, L., Huang, B. and Wu, G. (2015). 'Mapping science communication scholarship in China: Content analysis on breadth, depth and agenda of published research'. Public Understanding of Science 24 (8), pp. 897-912. DOI: $10.1177 / 0963662515600966$.

Lars Guenther received his doctorate at the Institute of Communication Research at Friedrich Schiller University in Jena, Germany, where he worked in research projects funded by the German Research Foundation in the priority program 1409 "Science and the Public". Currently, he is a postdoctoral fellow at the Research Chair in Science Communication at Stellenbosch University in South Africa. His research interests focus on science and health journalism, as well as the public communication of risks and (un)certainty. E-mail: larsguenther@sun.ac.za.

Marina Joubert is a science communication researcher and lecturer at CREST (Centre for Research on Evaluation, Science and Technology) at Stellenbosch University, South Africa, where she is part of a research team linked to the South African Research Chair in Science Communication. She holds a B.Sc. Food Science (Honours) degree, as well as a Journalism (honours) degree from Stellenbosch University, as well as an M.Sc. (Agric) from University of Pretoria. She is currently doing research on the factors affecting the public engagement behaviour of South African research leaders. E-mail: marinajoubert@sun.ac.za.

\section{How to cite}

Guenther, L. and Joubert, M. (2017). 'Science communication as a field of research: identifying trends, challenges and gaps by analysing research papers'.

JCOM 16 (02), A02. 